\title{
Selective Elimination of Parental Chromatin from Introgression Cultivars of xFestulolium (Festuca $\times$ Lolium)
}

\author{
David Kopecký $^{1}{ }^{1}$, Lucie Horáková ${ }^{1}$, Martin Duchoslav ${ }^{2} \mathbb{D}$ and Jaroslav Doležel ${ }^{1} \mathbb{D}$ \\ 1 Institute of Experimental Botany, Centre of the Region Haná for Biotechnological and Agricultural Research, \\ Šlechtitelů 31, 78371 Olomouc, Czech Republic; Lucinda.Horakova@seznam.cz (L.H.); \\ dolezel@ueb.cas.cz (J.D.) \\ 2 Department of Botany, Faculty of Science, Palacký University Olomouc, Šlechtitelů 27, \\ 78371 Olomouc, Czech Republic, martin.duchoslav@upol.cz \\ * Correspondence: kopecky@ueb.cas.cz;
}

Received: 13 May 2019; Accepted: 3 June 2019; Published: 4 June 2019

\begin{abstract}
Alien chromosome introgressions can be used to introduce beneficial traits from one species into another. However, exploitation of the introgressions in breeding requires proper transmission of introgressed segments to consecutive generations. In xFestulolium hybrids chromosomes of Festuca and Lolium readily pair and recombine. This opens a way for introgression of traits (e.g., abiotic and biotic stress resistance) from Festuca into elite Lolium cultivars. However, retention of Festuca chromatin in xFestulolium is uncertain as several studies indicated its gradual elimination over generations of sexual reproduction. Here we investigated genome composition in two subsequent generations of four introgression $\mathrm{xFestulolium}($. pratensis $\times$ L. multiflorum) cultivars using genomic in situ hybridization. We observed about 27-32\% elimination of Festuca chromatin in a single round of multiplication. At this pace, Festuca chromatin would be completely eliminated in about four generations of seed multiplication. On the other hand, we observed that it is possible to increase the proportion of Festuca chromatin in the cultivars by proper selection of mating plants. Nevertheless, once selection is relaxed, the first round of the seed multiplication reverts the genome composition back to the Lolium type. Thus, it seems that amphiploid forms of xFestulolium with relatively stable hybrid genomes may be more promising material for future breeding than introgression lines.
\end{abstract}

Keywords: genome dominance; ryegrass; fescue; hybrid; grass; recombination

\section{Introduction}

Interspecific or even intergeneric hybridization followed by whole genome duplication has been one of the main mechanisms of plant speciation, including many crop progenitors [1]. Besides ancient allopolyploids, such as wheat and cotton, new interspecific hybrids are produced in breeding programs to widen the gene pool of the crop species, to introgress beneficial traits from wild relatives to elite cultivars, or to combine agriculturally important traits from two different species (or genera). Merging the genomes from different species may disturb their organization and cooperation in the hybrid nucleus. In a majority of allopolyploids, the two parental genomes retain their integrity and their chromosomes (homoeologues) do not recombine via homoeologous chromosome pairing. This is usually controlled by specific genes or loci. Among them the Ph1 (Pairing homoeologous 1) system of wheat is the best known. Only plants with mutated, deleted or suppressed forms of meiotic pairing control genes enable incorporation of chromosome segments via homoeologous recombination $[2,3]$. However, in hybrids between some species, pairing of homoeologous chromosomes does take place and may be quite frequent. Van der Meer and De Vries reported successful hybridization between 
bulb onion (Allium cepa L.) and its wild relative A. roylei Stearn with the aim to introgress downy mildew resistance into elite cultivars of the bulb onion [4]. Similarly, chromosomes of ryegrass and fescue pair with each other in xFestulolium (Festuca $\times$ Lolium hybrids) [5]. The pairing results in extensive interspecies homoeologous recombination and chromosome reshuffling, and combined with reproduction by outcrossing, brings about enormous genetic diversity where each plant of a population has a different combination of segments of parental genomes. This creates an opportunity for breeders to introgress potentially any chromosomal segment from one species into the other. In this fashion many forms of xFestulolium were developed, including chromosome substitution and recombination lines [6]. Barnes et al. developed diploid L. perenne with introgression of F. pratensis chromatin in the distal part of the short arm of chromosome 3. Plants with this introgression were extremely drought resistant [7]. Similarly, Kosmala et al. reported introgression of freezing tolerance from F. pratensis into diploid L. multiflorum [8] and drought resistance was introduced from fescues into ryegrasses in several other breeding programs [9-11]. In general, the crossability of species from both genera enables the combination of high yield, palatability, digestibility and nutrition from ryegrasses and stress related traits (drought and freezing tolerance, winter hardiness, crown rust resistance) from fescues in xFestulolium hybrids [6].

On the other hand, promiscuous pairing of homoeologous chromosomes enables potential elimination of one of the parental genomes in successive sexual generations. In our previous study, we found that Lolium chromosomes were more abundant than those of Festuca in all screened amphiploid xFestulolium cultivars [12]. In some cultivars, the Festuca chromatin was completely eliminated. Zwierzykowski et al. observed gradual replacement of Festuca chromosomes by those of Lolium between F1 and F6 generations of L. multiflorum $\times$ F. pratensis hybrids [13]. One may speculate that the shift was due to the selection of 'Lolium-type' plants. Italian ryegrass, in comparison to meadow fescue, has a higher germination rate, faster seed germination and more rapid plant establishment from seed. Therefore, the same authors repeated the analysis on consecutive generations of L. multiflorum $\times F$. pratensis hybrids with random selection of progenies. Interestingly, they observed a similar trend of Lolium dominance, even though the shift was somewhat meager [14]. Genome dominance in interspecific hybrids is not unique to xFestulolium. Van Heusden et al. showed that in a hybrid of onion, one of the genomes (A. roylei) also appeared to be predominating: The frequency of roylei alleles in the F2 population was on average $56 \%$ (vs. $44 \%$ of cepa alleles) [15].

The mechanism(s) underlying genome dominance at the chromosomal level is so far unknown, and several scenarios have been hypothesized including gametic competition, pollination effects, selection for seed yield and germination, and meiotic drive in females [16]. Besides these, other aspects such as asynchrony of the meiotic rhythms may play a role, as evident in Brachiaria ruziziensis $\times$ B. brizantha hybrids [17]. The continuity of Festuca-chromatin elimination in advanced breeding material is questionable. In our previous work, we analyzed three consecutive generations of three registered amphiploid xFestulolium cultivars [18]. We found that despite high genetic variability within each population, the proportion of parental genomes was relatively stabilized without apparent Festuca-chromatin elimination in subsequent generations. Kubota et al. also did not observe a reduction in the proportion of the Festuca chromatin in successive generations of Japanese xFestulolium cultivars Icarus and Nakei 1 [19]. Similarly, Zwierzykowski et al. found that a shift in genome composition towards one of the parents appeared to reach a plateau between F7 and F8 generations [20]. The outcrossing mode of reproduction, accompanied by the potential Lolium-genome dominance, raised a question of the ability of Festuca chromatin to be transmitted into the subsequent generation(s) in the introgression xFestulolium cultivars, recently popular among grass breeders. To study this, we employed genomic in situ hybridization (GISH) to assess alien chromatin transmission in four cultivars under different management of progeny selection. 


\section{Materials and Methods}

\subsection{Plant Material}

We used four chromosome introgression cultivars of xFestulolium (labelled FL1-FL4) originating from the cross of L. multiflorum $\times$ F. pratensis. All four were at least in F6 after intergeneric hybridization. To estimate transmission frequencies of individual chromosomes, we used the progeny of tetraploid monosomic substitution lines $(2 \mathrm{n}=4 \mathrm{x}=28 ; 27 \mathrm{~L}+1 \mathrm{~F})$ developed in our previous study [21].

\subsection{Crossings and Selection}

Seeds were germinated in Petri dishes on wet filter paper and seedlings were planted in 30-mm pots in a greenhouse. After 3-4 weeks, plantlets were transferred to a hydroponic culture with an aerated solution of Hydroponex at $0.9 \mathrm{~g} / \mathrm{l}$ (Hu-Ben, Čerčany, Czech Republic) for root tip collection. Thereafter, the plantlets were transferred to pots $(20 \mathrm{~cm})$ in a greenhouse and inter-crossed under different regimes based on the presence of Festuca chromatin in the plants of the particular cultivar.

Cvs. FL1 and FL2 (all plants of the cultivar had at least a small proportion of the Festuca chromatin): About 25 plants were inter-pollinated and five seeds from each of the five randomly selected mother plants were germinated and analyzed ( 25 plants for each cultivar).

Cvs. FL3 and FL4 (only some plants carried Festuca chromatin, others were 'pure' Lolium): I. Pre-selection: 25 plants were analyzed and only plants with cytologically detectable Festuca chromatin were inter-crossed for each cultivar. Five seeds from each of the five randomly selected mother plants were germinated and analyzed (25 plants for each cultivar). II. Post-selection: Another 25 plants for each cultivar were analyzed and inter-crossed. Five seeds from each of ten mother plants (IIa/ five randomly selected plants having Festuca chromatin and $\mathrm{IIb}$ / five randomly selected plants without Festuca introgression) were germinated and analyzed (25+25 plants for each cultivar). The scheme of crossings and selections is given in Figure 1.

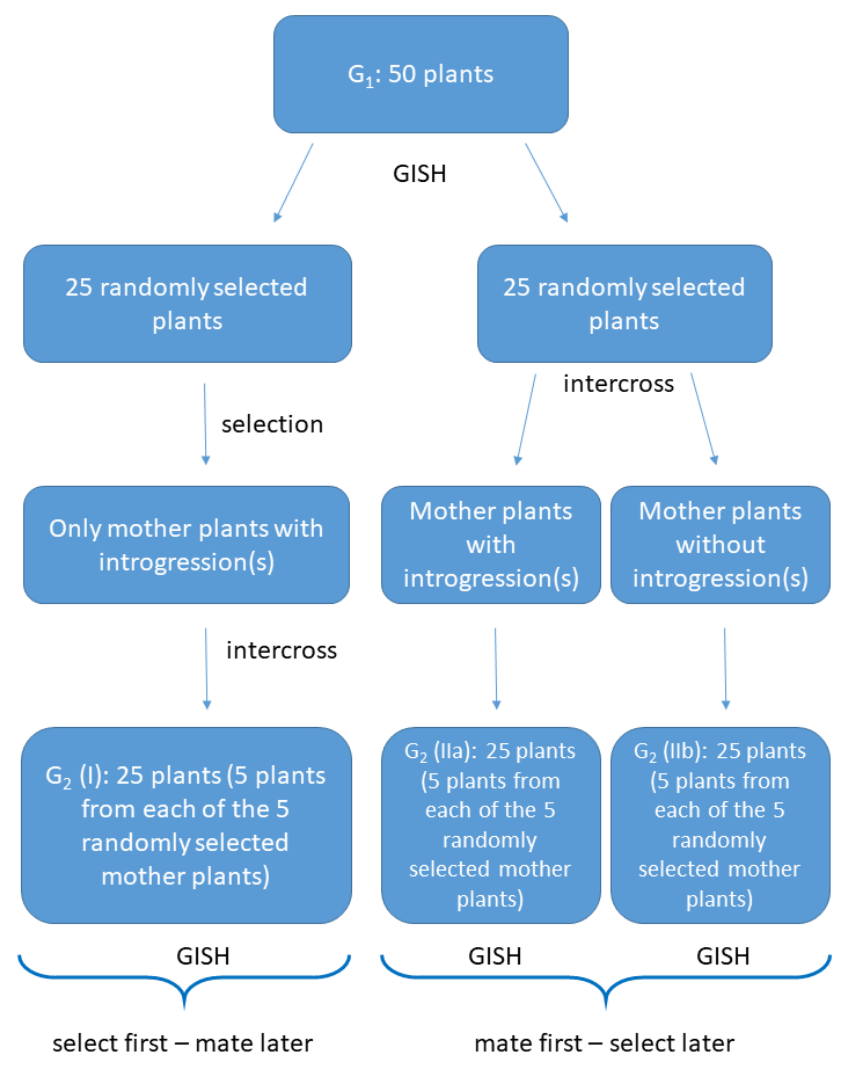

Figure 1. Scheme of crossings of cvs. FL3 and FL4. 


\subsection{Genomic in Situ Hybridization (GISH) and Microscopy}

Mitotic metaphase spreads and GISH were prepared from root tips according to Masoudi-Nejad et al. [22]. Total genomic DNA of $F$. pratensis was labelled with digoxigenin using DIG-Nick Translation Kit according to manufacturer's recommendation (Roche Applied Science, Penzberg, Germany) and used as a probe. Total genomic DNA of L. multiflorum was sheared to 200-500-bp fragments by boiling for $45 \mathrm{~min}$ and used as blocking DNA. The probe to block ratio was 1:150 with minor variation. Sites of probe hybridization were detected by the Anti-DIG-FITC conjugate (Roche). Chromosomes were counterstained with $1.5 \mu \mathrm{g} / \mathrm{ml}$ 4',6-diamidino-2-phenylindole (DAPI) in Vectashield antifade solution (Vector Laboratories, Burlingame, CA, USA). Slides were evaluated with Olympus AX70 epifluorescent microscope equipped with a SensiCam B/W camera. ScionImage and Adobe Photoshop software were used for processing of color pictures. At least three metaphase spreads were evaluated for each plant. We counted the number of Festuca and Lolium chromosomes, both with and without homoeologous exchange(s). Centromere identity was used to assign a particular chromosome to one of the two parental genomes. Thus, the chromosome was identified as of Festuca-origin if its centromere was labelled with F. pratensis probe even if the majority of the chromosome consisted of the Lolium chromatin.

The parental generation was designated $G_{1}$ and the following generation after intercross of $G_{1}$ was designated $G_{2}$. In cultivars FL3 and FL4, three types of $G_{2}$ were analyzed: $G_{2} / I, G_{2} / I I a$ and $G_{2} / \mathrm{Ilb}$ (Figure 1 ).

\subsection{Data Analysis}

Rates of alien chromatin elimination in introgression forms were compared between generations $\mathrm{G}_{1}$ and $\mathrm{G}_{2}$ using the following procedure. Genome composition was represented as a number of Lolium (L) and Festuca (F) chromosomes, classified into four groups: L or F complete and L or F recombined. In the first step, we calculated the expected (theoretical) genome composition of offspring from each mother plant as arithmetic means of genome composition of respective mother and averaged genome composition of males used in cross pollination. This approach was chosen because the plant origin of pollen was not known. Subsequently, the expected genome composition was compared with the actual genome composition determined using GISH, separately for each group (L or F complete and $\mathrm{L}$ or $\mathrm{F}$ translocated) and cultivar. For statistical evaluation, the two-sided paired t-test was used in NCSS 9 software (NCSS, LLC., Kaysville, Utah, USA, ncss.com/software/ncss). Each mother plant represented a block with paired values: Expected and observed chromosome numbers. We tested $\mathrm{H}_{0}$ that both expected and observed chromosome numbers were equal (that is, there were no changes of genome composition between two consecutive generations). We also calculated the mean percentage change in proportional representation of each group of chromosomes ( $\mathrm{L}$ or $\mathrm{F}$ complete and $\mathrm{L}$ or $\mathrm{F}$ translocated) in the total genome composition between consecutive generations in each cultivar $\left(G_{2}-G_{1}\right)$ (Tables 1-3). Positive/negative values represent increase/decrease in proportional representation of respective genome groups in the total genome composition.

\section{Results}

All four cultivars (FL1-FL4) showed high levels of aneuploidy. Chromosome numbers ranged from 25 to 30 , and only $35 \%$ of plants were euploid $(2 n=4 x=28)$. The most frequent karyotype was $2 n=27$ (observed in 39\% of plants). Interestingly, the frequency of aneuploidy decreased in the subsequent generation in three cultivars: from 77.3 to $70.8 \%$ in FL2, from 64.3 to $56.8 \%$ in FL3 and from 70.0 to $66.7 \%$ in FL4. In cv. FL1, aneuploidy was stable over the generations (60\%).

\subsection{Cultivars with Higher Proportion of Festuca chromatin (FL1 and FL2)}

All G1 plants of cultivars FL1 and FL2 carried some Festuca chromatin (Figure 2). We detected 4.35 and 3.14 chromosomes with homoeologous recombination event(s) and 0.50 and 0.36 complete Festuca chromosomes in FL1 and FL2, respectively. Among the recombined chromosomes, 3.55 and 2.32 were of Lolium-origin (with centromeres from the Lolium genome), whereas only 0.80 and 0.82 
were of Festuca-origin. In both cultivars, we found a replacement of Festuca-origin chromosomes by those of Lolium-origin in the G2 generation). While all plants of the G1 generation had at least some Festuca chromatin, we found 4 and 3 'pure' Lolium plants (out of 25) without detectable Festuca chromatin in the G2 generation of FL1 and FL2, respectively. The genome composition changed from $26.05 \mathrm{~L}+1.30 \mathrm{~F}$ (where L designates Lolium-origin chromosomes and F Festuca-origin chromosomes) to $26.4 \mathrm{~L}+0.84 \mathrm{~F}$ in FL1 and from $26.0 \mathrm{~L}+1.18 \mathrm{~F}$ to $26.67 \mathrm{~L}+0.58 \mathrm{~F}$ in FL2 (Table 1). The number of translocated chromosomes dropped from 4.35 to 3.20 in FL1 and from 3.14 to 2.42 in FL2. The most dramatic (and statistically significant) was the elimination of complete Festuca chromosomes: From 0.5 to 0.16 and from 0.36 to 0.04 in FL1 and FL2, respectively. Thus, the overall reduction of Festuca chromatin from generation to generation was about 27\% in FL1 and 32\% in FL2 (Figure 3).
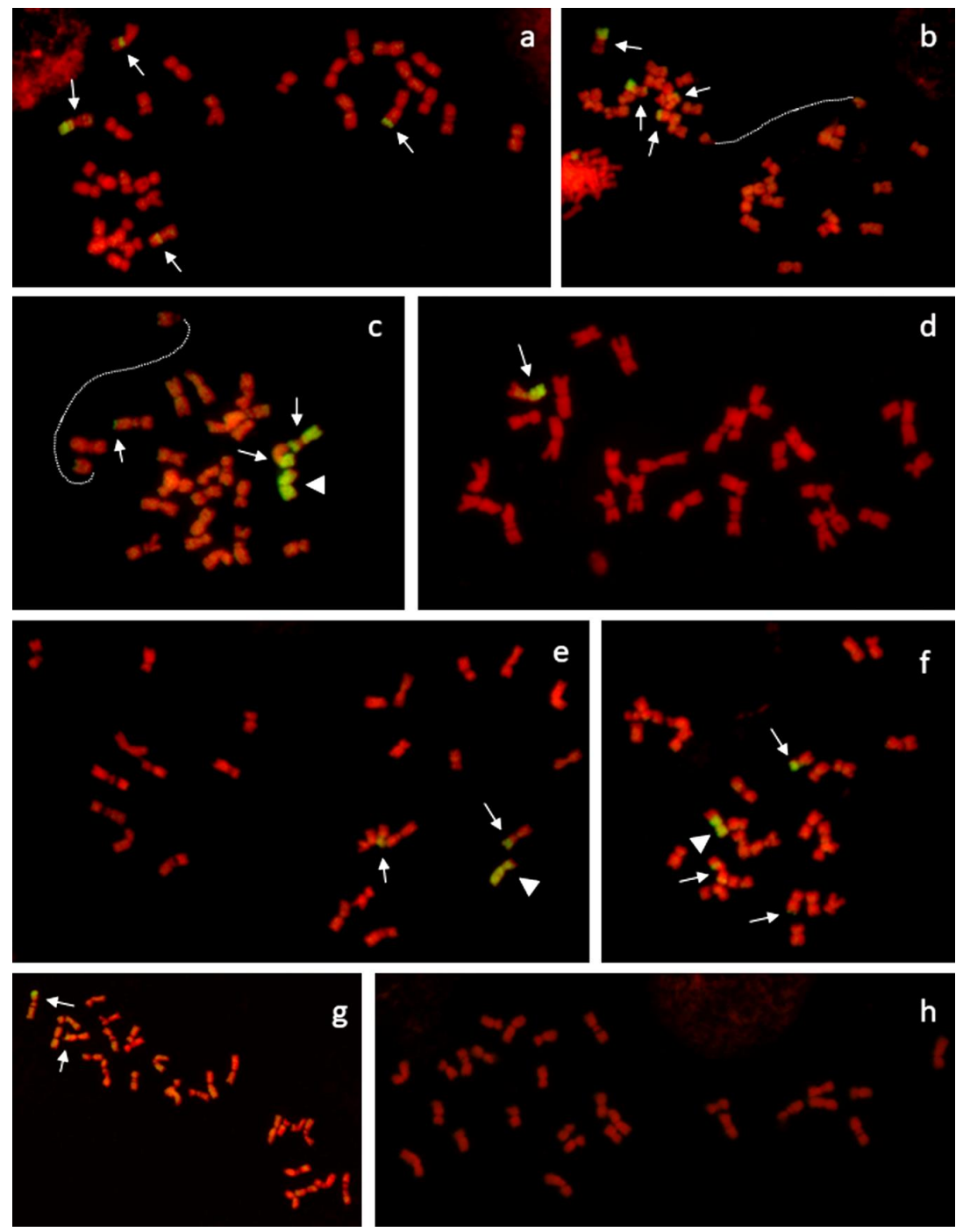

Figure 2. The analysis of genome constitution in four xFestulolium cultivars by in situ hybridization. GISH was done on mitotic metaphase spreads of L. multiflorum $\times$ F. pratensis cultivars FL1 (a-b), FL2 (c-d), FL3 (e-f), and FL4 (g-h) over two generations $\left(\mathrm{G}_{1}: \mathrm{a}, \mathrm{c}, \mathrm{e}, \mathrm{g}\right.$ and $\left.\mathrm{G}_{2}: \mathrm{b}, \mathrm{d}, \mathrm{f}, \mathrm{h}\right)$. Total genomic DNA of $F$. pratensis was labeled with FITC and used as a probe (yellow-green color); unlabeled genomic DNA of L. multiflorum was used to block hybridization of sequences common to both species. Chromosomes were counterstained by DAPI (red pseudocolor). Chromosomes with homoeologous translocation(s) are arrowed (of Lolium-origin: With centromeres from Lolium) while arrowheads point to Festuca-origin chromosomes (that is those with centromeres from Festuca). Dotted lines connect parts of single chromosomes broken in primary (centromere) or secondary (NOR) constriction. 


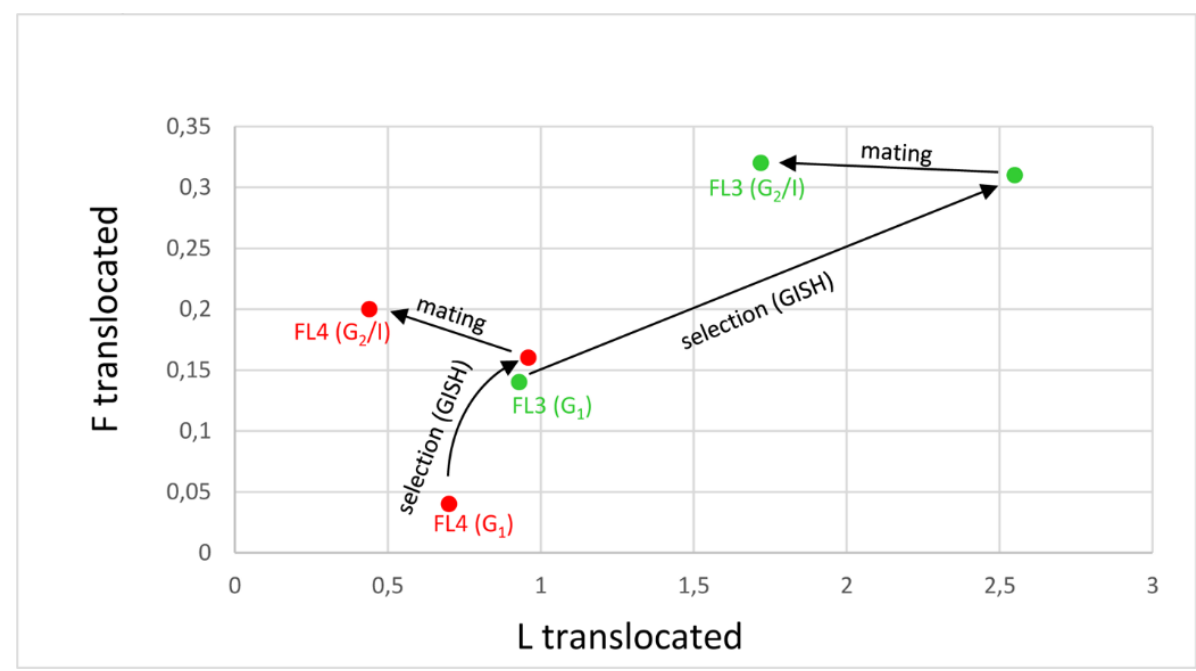

Figure 3. The shift in genome composition in xFestulolium cultivars FL3 and FL4. Plants of $\mathrm{G}_{1}$ generation were analyzed by GISH and only those with a translocation(s) were used for mating. Note that it is possible to manipulate genome composition of the cultivar and increase the proportion of Festuca chromatin (either in the form of Lolium chromosomes with translocated Festuca segments, or as Festuca chromosomes with translocated Lolium segments) by selection of mating plants (using GISH). However, the first round of seed multiplication shifts the genome composition back towards the Lolium genome. $\mathrm{x}$ and $\mathrm{y}$ axes: F translocated refers to the number of Festuca chromosomes with Lolium translocation(s) and L translocated refers to number of Lolium chromosomes with Festuca translocation(s).

Table 1. Genome constitution in xFestulolium cultivars FL1 and FL2. All $25 \mathrm{G}_{1}$ plants from each cultivar were evaluated by GISH $\left(\mathrm{G}_{1}\right.$ male). Five randomly selected mother plants $\left(\mathrm{G}_{1}\right.$ female) were used for seed collection (five seeds from each mother plant). The 25 plants of the $G_{2}$ generation for each cultivar were screened by GISH. Numbers in the table represent the number of Lolium-origin (L) or Festuca-origin (F) chromosomes. Differences in genome composition between $\mathrm{G}_{1}$ and $\mathrm{G}_{2}$ generations were tested separately for each $\mathrm{L}$ and $\mathrm{F}$ chromosome group by the paired t-test. Significant differences are marked by asterisks. Arrows denote direction of change in genome composition between real and expected genome composition of $\mathrm{G}_{2}$ plants.

\begin{tabular}{ccccc}
\hline Cultivar & L complete & L translocated & F translocated & F complete \\
\hline FL1 $\mathrm{G}_{1}$ (male) & $22.50 \pm 2.97$ & $3.55 \pm 2.33$ & $0.80 \pm 0.98$ & $0.50 \pm 0.87$ \\
FL1 G $\mathrm{F}_{1}$ female & $22.80 \pm 2.14$ & $3.20 \pm 1.17$ & $0.80 \pm 1.30$ & $0.40 \pm 0.89$ \\
FL1 G $\mathrm{G}_{2}$ & $23.77 \pm 2.23^{* *} \uparrow$ & $2.52 \pm 2.16^{*} \downarrow$ & $0.68 \pm 0.74$ & $0.16 \pm 0.47^{*} \downarrow$ \\
Change in proportion $\mathrm{G}_{2}-\mathrm{G}_{1}(\%)$ & 4.59 & -3.10 & -0.43 & -1.06 \\
FL2 $\mathrm{G}_{1}$ (male) & $23.68 \pm 1.61$ & $2.32 \pm 1.06$ & $0.82 \pm 0.98$ & $0.36 \pm 0.64$ \\
FL2 $\mathrm{G}_{1}$ female & $23.75 \pm 2.06$ & $2.25 \pm 1.25$ & $1.25 \pm 1.89$ & $0.25 \pm 0.50$ \\
FL2 $\mathrm{G}_{2}$ & $24.83 \pm 1.31^{(*)} \uparrow$ & $1.88 \pm 1.48$ & $0.54 \pm 0.72 \downarrow \downarrow$ & $0.04 \pm 0.20^{* * *} \downarrow$ \\
Change in proportion $\mathrm{G}_{2}-\mathrm{G}_{1}(\%)$ & 4.29 & -1.48 & -1.82 & -0.99 \\
\hline
\end{tabular}

$\mathrm{L}=$ Lolium chromosome;

$\mathrm{F}=$ Festuca chromosome;

translocated $=$ chromosome bearing homoeologous translocation $(\mathrm{s})$;

(*) $P \leq 0.10, * P \leq 0.05,{ }^{* *} P \leq 0.01,{ }^{* * *} P \leq 0.001$.

\subsection{Cultivars with Lower Proportions of Festuca chromatin (FL3 and FL4)}

In cultivars FL3 and FL4, only some plants had at least a single chromosome segment from F. pratensis (19 out of 50 in FL3 and 29 out of 80 in FL4), while other plants had a pure L. multiflorum genome. There was not a single plant carrying a complete Festuca chromosome in these cultivars. The number of chromosomes with evidence of homoeologous recombination was low: 0.78 and 0.74 in 
FL3 and FL4, respectively. Among those, the majority were of Lolium-origin (0.64 vs. 0.14 in FL3 and 0.70 vs. 0.04 in FL4).

Two different ways of multiplication were used: First selection-second intercross $\left(G_{2} / I\right)$ and first intercross - second selection $\left(\mathrm{G}_{2} / \mathrm{II}\right.$ and $\left.\mathrm{G}_{2} / \mathrm{IIb}\right)$. In the first one, plants were phenotyped by GISH and only plants having homoeologous translocation(s) were used for mating. This altered the pattern of parental genomes from $26.68 \mathrm{~L}+0.88 \mathrm{~T}\left(0.64^{\mathrm{L}}+0.14^{\mathrm{F}}\right)$ to $25.00 \mathrm{~L}+2.72 \mathrm{~T}\left(2.43^{\mathrm{L}}+0.29^{\mathrm{F}}\right)$ in $\mathrm{FG} 1$ and from $26.34 \mathrm{~L}+0.74 \mathrm{~T}\left(0.70^{\mathrm{L}}+0.04^{\mathrm{F}}\right)$ to $25.78 \mathrm{~L}+1.22 \mathrm{~T}\left(1.11^{\mathrm{L}}+0.11^{\mathrm{F}}\right)$ in FL4. However, the intercross of selected plants with homoeologous translocation(s) did not ensure stabilization of the translocation(s). We found that only $21(84 \%)$ and $12(48 \%)$ out of 25 progeny plants (G2/I) carried translocation(s) in FL3 and FL4, respectively. The overall level of Festuca chromatin was reduced to $25.58 \mathrm{~L}+25.04 \mathrm{~T}$ $\left(1.72^{\mathrm{L}}+0.32^{\mathrm{F}}\right)$ in FL3 and to $26.36 \mathrm{~L}+0.64 \mathrm{~T}\left(0.44^{\mathrm{L}}+0.20^{\mathrm{F}}\right)$ in FL4 (Table 2). The major contributor to the elimination was the replacement of Lolium chromosomes with translocation(s) to complete Lolium chromosomes (statistically significant in both cultivars). The number of Festuca chromosomes with translocation(s) was relatively stable over the two generations.

In the second regime of multiplication, we first intercrossed all 25 plants and after mating, we collected seeds from five mother plants carrying homoeologous translocation(s), and from five mother plants without any such translocation. There was no statistically significant change in the number of Lolium and Festuca chromosomes in progeny of plants with translocation(s) (G2/IIa), even though a slight increase of Festuca chromatin was observed in both cultivars (Table 3). However, only 16 and 19 out of 25 plants had translocation(s) in FL3 and FL4, respectively. Among the progenies of mother plants without translocation(s), there were only one and two out of 25 plants with translocation(S) in FL3 and FL4, respectively. In both cultivars, there was a statistically significant difference between the expected and observed number of translocated chromosomes (always of Lolium-origin). It appears that mother plants tended to be pollinated by pollen from the same group in both cultivars: Plants with translocation(s) were more frequently pollinated with the plants having translocation(s) and the 'pure' Lolium plant was preferentially pollinated with other 'pure' Lolium plants.

Table 2. Genome constitution in xFestulolium cultivars FL3 and FL4 with first selection-second intercross management. The plants were first genotyped by GISH and only plants with Festuca chromatin $\left(G_{1}\right.$ male) were used for mating. Five randomly selected mother plants $\left(G_{1}\right.$ female) were used for collection of seeds (five seeds from each mother plant). The 25 plants of $G_{2}$ generation $\left(G_{2} / I\right)$ for each cultivar were screened by GISH. The numbers in the table represent either the number of Lolium-origin (L) or Festuca-origin (F) chromosomes. Differences in genome composition between the $G_{1}$ and $G_{2}$ generations were tested separately for each $L$ and $F$ chromosome group by the paired t-test. Significant differences are marked by asterisks. Arrows denote direction of change in genome composition between real and expected genome composition of $\mathrm{G}_{2}$ plants. Note that no complete Festuca chromosome was detected in the cultivars FL3 and FL4.

\begin{tabular}{cccc}
\hline Cultivar & L complete & L translocated & F translocated \\
\hline FL3 $\mathrm{G}_{1}$ male for $\mathrm{G}_{2} / \mathrm{I}$ & $25.00 \pm 2.39$ & $2.43 \pm 1.99$ & $0.29 \pm 0.70$ \\
FL3 $\mathrm{G}_{1}$ female for $\mathrm{G}_{2} / \mathrm{I}$ & $24.67 \pm 2.66$ & $2.67 \pm 2.25$ & $0.33 \pm 0.81$ \\
FL3 $\mathrm{G}_{2} / \mathrm{I}$ & $25.58 \pm 1.28^{* * \uparrow}$ & $1.72 \pm 1.14^{* * *} \downarrow$ & $0.32 \pm 0.62$ \\
Change in proportion $\mathrm{G}_{2}-\mathrm{G}_{1}(\%)$ & 2.94 & -2.98 & 0.04 \\
FL4 $\mathrm{G}_{1}$ male for $\mathrm{G}_{2} / \mathrm{I}$ & $25.78 \pm 0.92$ & $1.11 \pm 0.74$ & $0.11 \pm 0.31$ \\
FL4 $\mathrm{G}_{1}$ female for $\mathrm{G}_{2} / \mathrm{I}$ & $26.40 \pm 0.55$ & $0.80 \pm 0.45$ & $0.20 \pm 0.44$ \\
FL4 $\mathrm{G}_{2} / \mathrm{I}$ & $26.36 \pm 1.22$ & $0.44 \pm 0.77^{* *} \downarrow$ & $0.20 \pm 0.41$ \\
Change in proportion $\mathrm{G}_{2}-\mathrm{G}_{1}(\%)$ & 1.75 & -1.90 & 0.15 \\
\hline
\end{tabular}

$\mathrm{L}=$ Lolium chromosome;

$\mathrm{F}=$ Festuca chromosome;

translocated $=$ chromosome bearing homoeologous translocation(s);

${ }^{* *} P \leq 0.01,{ }^{* * *} P \leq 0.001$. 
Table 3. Genome constitution in xFestulolium cultivars FL3 and FL4 with first intercross-second selection management. Plants of $G_{1}$ generation were genotyped by GISH and intercrossed. The $G_{1}$ plants were thereafter split into two groups: Those with translocations and those without translocation(s). Five randomly selected mother plants from each group (female for G2/IIa and female for G2/IIb) were used for seed collection (five seeds from each mother plant). The plants of $G_{2}$ generation ( 25 for $G_{2} / I_{1}$ and 25 for $\mathrm{G}_{2} / \mathrm{IIb}$ ) were screened by GISH. The numbers in the table represent either the number of Lolium-origin (L) or Festuca-origin (F) chromosomes. Differences in the genome composition between $G_{1}$ and $G_{2}$ generations were tested separately for each $L$ and $F$ chromosome group by the paired t-test. Significant differences are marked by asterisks. Arrows denote direction of change in genome composition between real and expected genome composition of $G_{2}$ plants.

\begin{tabular}{|c|c|c|c|}
\hline Cultivar & L complete & $\mathrm{L}$ translocated & F translocated \\
\hline FL3 $G_{1}$ male for G2/II & $26.86 \pm 1.52$ & $0.43 \pm 0.79$ & $0.10 \pm 0.29$ \\
\hline FL3 $G_{1}$ female for G2/IIa & $25.60 \pm 1.94$ & $1.60 \pm 0.89$ & $0.40 \pm 0.54$ \\
\hline $\mathrm{FL} 3 \mathrm{G}_{2} / \mathrm{IIa}$ & $25.79 \pm 2.06$ & $1.21 \pm 1.14$ & $0.33 \pm 0.48$ \\
\hline Change in proportion $\mathrm{G}_{2}-\mathrm{G}_{1}(\%)$ & -1.02 & 0.72 & 0.30 \\
\hline FL3 $G_{1}$ female for $\mathrm{G} 2 / \mathrm{IIb}$ & $28.40 \pm 1.52$ & $0.00 \pm 0.00$ & $0.00 \pm 0.00$ \\
\hline $\mathrm{FL} 3 \mathrm{G}_{2} / \mathrm{Ill}$ & $27.64 \pm 1.18$ & $0.04 \pm 0.20^{* * *} \downarrow$ & $0.00 \pm 0.00$ \\
\hline Change in proportion $\mathrm{G}_{2-} \mathrm{G}_{1}(\%)$ & 0.82 & -0.64 & -0.18 \\
\hline $\mathrm{FL}_{4} \mathrm{G}_{1}$ male for $\mathrm{G} 2 / \mathrm{II}$ & $26.46 \pm 0.94$ & $0.61 \pm 0.66$ & $0.02 \pm 0.15$ \\
\hline FL4 $\mathrm{G}_{1}$ female for G2/IIa & $26.20 \pm 0.44$ & $1.20 \pm 0.44$ & $0.00 \pm 0.00$ \\
\hline $\mathrm{FL} 4 \mathrm{G}_{2} / \mathrm{IIa}$ & $25.96 \pm 1.06^{(*)} \uparrow$ & $1.36 \pm 0.99 * \uparrow$ & $0.00 \pm 0.00$ \\
\hline Change in proportion $\mathrm{G}_{2-} \mathrm{G}_{1}(\%)$ & -1.60 & 1.64 & -0.04 \\
\hline FL4 $G_{1}$ female for $\mathrm{G} 2 / \mathrm{IIb}$ & $27.00 \pm 0.71$ & $0.00 \pm 0.00$ & $0.00 \pm 0.00$ \\
\hline $\mathrm{FL} 4 \mathrm{G}_{2} / \mathrm{IIb}$ & $26.76 \pm 1.09$ & $0.08 \pm 0.28^{* * *} \downarrow$ & $0.00 \pm 0.00$ \\
\hline Change in proportion $\mathrm{G}_{2}-\mathrm{G}_{1}(\%)$ & 0.89 & -0.85 & -0.04 \\
\hline
\end{tabular}

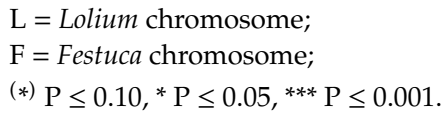

\subsection{Transmission of Individual F. pratensis chromosomes in Consecutive Generation}

Using tetraploid monosomic substitution lines, where one Lolium chromosome was replaced by its Festuca homoeologue, we analyzed the transmission frequency of individual chromosomes. There was a clear variation in the transmission rate among different chromosomes: Chromosome 5F was transmitted to the progeny at only 34\% frequency (significantly less than expected 50\%), while other chromosomes were transmitted almost regularly (Table 4). However, not a single F. pratensis chromosome was transmitted to the progeny with frequency above the expected 50\%. So, besides the more frequently eliminated chromosome 5F, all Festuca chromosomes contribute to the general gradual elimination of the Festuca chromatin from the hybrid genome.

Table 4. Transmission of individual chromosomes in monosomic substitution lines $(2 \mathrm{n}=4 \mathrm{x}=28 ; 27 \mathrm{~L}+1 \mathrm{~F})$.

\begin{tabular}{ccc}
\hline Chromosome & Number of plants & Transmission (\%) \\
\hline $1 \mathrm{~F}$ & 111 & $46^{\text {n.s. }}$ \\
$2 \mathrm{~F}$ & 96 & $49^{\text {n.s. }}$ \\
$3 \mathrm{~F}$ & 114 & $44^{\text {n.s. }}$ \\
$4 \mathrm{~F}$ & 88 & $47^{\text {n.s. }}$ \\
$5 \mathrm{~F}$ & 88 & $34^{\text {** }}$ \\
$6 \mathrm{~F}$ & 131 & $48^{\text {n.s. }}$ \\
7F & 136 & $48^{\text {n.s. }}$ \\
\hline
\end{tabular}

n.s. non-significant;

** significant deviation from the expected transmission frequency (0.50) at $P \leq 0.01$ (Student's t-test). 


\section{Discussion}

Wide hybridization offers a possibility to transfer chromosomes or chromosome segments with beneficial alleles from one species to another. However, for further exploitation of the introgression lines in breeding programs, they must be fertile and chromosomally stable. Homoeologous chromosomes generally do not pair and recombine in interspecific hybrids. This theoretically prevents alien chromosomes, when disomic, from being eliminated from the host genome. However, this is not always the case. Orellana et al. [23] found reduced metaphase I pairing of rye chromosomes and significantly higher numbers of rye univalents compared to wheat chromosomes in disomic additions and substitutions of rye chromosomes in wheat. This led to the elimination of rye chromosomes. This was most probably a consequence of disturbed migration of rye telomeres into the leptotene bouquet [24] as an extension of their erratic behavior in somatic tissues [25].

The absence of a chromosome pairing regulator such as Ph1 in wheat, and sufficient sequence homology between homoeologues, opens the way for direct competition of homoeologues in hybrids. Such a rivalry frequently (if not always) leads to rapid or gradual elimination (or replacement) of the chromosomal complement from one of the parents. If a "submissive" parental genome is the source of chromosomes to be introgressed, as is the case in xFestulolium hybrids, the risk of its elimination in subsequent generations seems to be enormous. Pickering [26] reported elimination of Hordeum bulbosum chromosomes in monosomic substitution lines of $H$. bulbosum $\times H$. vulgare. The frequency of the elimination in the hybrids seemed to be tissue-specific and temperature-dependent [27]. Moreover, the preferential elimination of some chromosomes and higher transmission of others was observed also in Gossypium hirsutum $\times$ G. australe and G. hirsutum $\times$ G. sturtianum hybrids [28]. We found a similar phenomenon in this study: Chromosome $5 \mathrm{~F}$ was transmitted to only $34 \%$ of the progeny, while chromosomes $2 \mathrm{~F}, 6 \mathrm{~F}$ and $7 \mathrm{~F}$ were transmitted almost regularly $(48-49 \%)$. This may further hamper the stable incorporation of the traits located on the preferentially-eliminated chromosomes.

Based on the elimination rate from $G_{1}$ (parental generation) to $G_{2}$ (subsequent generation after intercross of $G_{1}$ ) in the xFestulolium cultivars investigated in this study, we predict that without a selection, and with the same elimination rate, Festuca chromatin will be completely eliminated after four generations of multiplication. The reversion of the hybrid genome to the parental ('pure' Lolium) form has already taken place in several xFestulolium cultivars, where no Festuca chromatin was observed after GISH [12]. Similarly, King et al. [29] found much higher transmission of complete Lolium chromosomes compare to complete Festuca chromosomes in the successive generation after backcross of diploid monosomic substitution lines of L. perenne $\times F$. pratensis $(13 \mathrm{~L}+1 \mathrm{~F}$, the proportion was 89:11, instead of expected 1:1). Unfortunately, authors did not indicate the parental origin of the translocated chromosomes. Thus, the overall Festuca chromatin elimination could not be assessed from their study. However, the complete elimination may not always be so rapid in all xFestulolium hybrids. It was evidenced earlier that different combinations of parental species used for interspecific hybridization display different frequency of homoeologous chromosome pairing. We found that L. multiflorum $\times$ F. glaucescens hybrids displayed much less homoeologous recombination events than those of L. multiflorum $\times$ F. pratensis [12]. Moreover, the chromosome segment may retain and persist within populations of the subsequent generations because of the selective advantage. The cultivar AberNile with $a$ F. pratensis introgression on chromosome 5 bearing stay-green mutation admittedly with the recessive gene present in disomic form and drought tolerant cultivar AberLink with a single F. glaucescens introgression on chromosome 3 display genetic stability over many generations (Prof. Mike Humphreys, personal communication).

Interestingly, it seems that mother plants were preferentially pollinated by pollen from the same group in both cultivars: Plants with translocation(s) were more frequently pollinated with the plants having translocation(s) and 'pure' Lolium plant was preferentially pollinated with another 'pure' Lolium plant. We can only speculate on the mechanisms underlying this phenomenon. One may hypothesize that it is caused by the asynchrony in the flowering time of the plants with and without homoeologous translocation(s) or by the (probably meager) action of the potential genetic barrier(s) between both 
groups of plants. This preferential mating may also play a role in the stabilized transmission of the Festuca segment(s) to successive generations.

Instability of Festuca introgressions contrasts with the relative stability of amphiploid xFestulolium cultivars. In our previous work, we confirmed that amphiploid L. multiflorum $\times$ F. pratensis cultivars were relatively stable over three consecutive generations. Despite a large variability within the populations, the genomic composition did not change significantly, and the Festuca chromatin was not eliminated any further [18]. Similarly, Zwierzykowski et al. reported that chromosomes of F. pratensis were gradually replaced by those of L. multiflorum in six consecutive generations of hybrids but became stabilized in the F7-F8 generations without any additional elimination of Festuca chromatin [20]. Interestingly, genome composition was stabilized in the proportion of about 65:35 in favor of the Lolium genome, the proportion very similar to that of stabilized amphiploid xFestulolium cultivars [12]. Based on the present evidence, we are not able to accurately distinguish between the cause and the effect: If this is a naturally stable proportion of parental genomes, or if the 65:35 proportion was reached as a consequence of 6-8 rounds of multiplication (and potential selection) during which the hybrid genome was stabilized.

To conclude, our study shows a rapid elimination of the Festuca chromatin in introgression cultivars of $x$ Festulolium (L. multiflorum $\times$ F. pratensis). Without any selection and if the introgressed segment does not bring a strong selective advantage, such cultivars will most likely revert to the 'pure' Lolium constitution within about four generations of multiplication. This may prevent their further utilization in grass breeding. From the practical viewpoint, amphiploids with relatively stable hybrid genome constitutions appear to be a more promising material for future breeding. From the evolutionary viewpoint, it would be interesting to investigate the reverse situation: Transmission of Lolium chromosome segments in introgression forms of xFestulolium, where the Festuca genome predominates (where one or more backcrosses of F1 hybrids to Festuca were used). As the Lolium genome is the dominant one in hybrids, one may speculate on higher stability of Lolium introgressions as compared to those (Festuca introgressions) used in this study.

Author Contributions: Conceptualization, D.K. and J.D.; Methodology, D.K. and L.H.; Formal Analysis, D.K. and L.H.; Investigation, D.K. and L.H.; Resources, D.K.; Data Curation, D.K. and M.D.; Writing - Original Draft Preparation, D.K.; Writing - Review \& Editing, M.D. and J.D.; Visualization, D.K. and L.H.; Supervision, D.K.; Project Administration, D.K.; Funding Acquisition, D.K. and J.D.

Funding: This research was funded by the Czech Science Foundation (grant award 17-13853S) and by the European Regional Development Fund OPVVV project "Plants as a tool for sustainable development" number CZ.02.1.01/0.0/0.0/16_019/0000827 supporting Excellent Research at CRH.

Acknowledgments: We would like to thank Helena Tvardíková and Radka Tušková for excellent technical support. We express our thank you to Prof. Adam J. Lukaszewski (University of California, Riverside) for his critical reading and valuable comments.

Conflicts of Interest: The authors declare no conflict of interest.

\section{References}

1. Soltis, P.S.; Soltis, D.E. The Role of Hybridization in Plant Speciation. Annu. Rev. Plant Biol. 2009, 60, 561-588. [CrossRef] [PubMed]

2. Sears, E.R.; Okamoto, M. Intergenomic chromosome relationships in hexaploid wheat. In Proceedings of the 10th International Congress of Genetics, Montreal, QC, Canada, 20-27 August 1958; pp. 258-259.

3. Riley, R.; Chapman, V. Genetic control of the cytologically diploid behavior of hexaploid wheat. Nature 1958, 182, 713-715. [CrossRef]

4. Vandermeer, Q.P.; Devries, J.N. An interspecific cross between Allium roylei Stearn. and Allium cepa L. and its backcross to Allium cepa. Euphytica 1990, 47, 29-31. [CrossRef]

5. Kopecky, D.; Lukaszewski, A.J.; Dolezel, J. Meiotic behaviour of individual chromosomes of Festuca pratensis in tetraploid Lolium multiflorum. Chromosome Res. 2008, 16, 987-998. [CrossRef] [PubMed]

6. Kopecky, D.; Lukaszewski, A.J.; Dolezel, J. Cytogenetics of festulolium (Festuca x Lolium hybrids). Cytogenet. Genome Res. 2008, 120, 370-383. [CrossRef] [PubMed] 
7. Barnes, B.D.; Kopecky, D.; Lukaszewski, A.J.; Baird, J.H. Evaluation of Turf-type Interspecific Hybrids of Meadow Fescue with Perennial Ryegrass for Improved Stress Tolerance. Crop Sci. 2014, 54, 355-365. [CrossRef]

8. Kosmala, A.; Zwierzykowski, Z.; Gasior, D.; Rapacz, M.; Zwierzykowska, E.; Humphreys, M.W. GISH/FISH mapping of genes for freezing tolerance transferred from Festuca pratensis to Lolium multiflorum. Heredity 2006, 96, 243-251. [CrossRef]

9. Humphreys, M.W.; Thomas, H. Improved drought resistance in introgression lines derived from Lolium multiflorum x Festuca arundinacea hybrids. Plant Breed. 1993, 111, 155-161. [CrossRef]

10. Humphreys, M.W.; Pasakinskiene, I. Chromosome painting to locate genes for drought resistance transferred from Festuca arundinacea into Lolium multiflorum. Heredity 1996, 77, 530-534. [CrossRef]

11. Lesniewska, A.; Ponitka, A.; Slusarkiewicz-Jarzina, A.; Zwierzykowska, E.; Zwierzykowski, Z.; James, A.R.; Thomas, H.; Humphreys, M.W. Androgenesis from Festuca pratensis x Lolium multiflorum amphidiploid cultivars in order to select and stabilize rare gene combinations for grass breeding. Heredity 2001, 86, 167-176. [CrossRef]

12. Kopecky, D.; Loureiro, J.; Zwierzykowski, Z.; Ghesquiere, M.; Dolezel, J. Genome constitution and evolution in Lolium x Festuca hybrid cultivars (Festulolium). Theor. Appl. Genet. 2006, 113, 731-742. [CrossRef] [PubMed]

13. Zwierzykowski, Z.; Kosmala, A.; Zwierzykowska, E.; Jones, N.; Joks, W.; Bocianowski, J. Genome balance in six successive generations of the allotetraploid Festuca pratensis x Lolium perenne. Theor. Appl. Genet. 2006, 113, 539-547. [CrossRef] [PubMed]

14. Zwierzykowski, Z.; Ksiazczyk, T.; Taciak, M.; Zwierzykowska, E.; Jones, N.; Kosmala, A. Genome constitution in selected and unselected plants of F2-F4 generations derived from an allotet-raploid Festuca pratensis x Lolium perenne hybrid. In Breeding Strategies for Sustainable Forage and Turf Grass Improvement; Barth, S., Milbourne, D., Eds.; Springer: Amsterdam, The Netherland, 2012; pp. 75-79.

15. Van Heusden, A.W.; van Ooijen, J.W.; Vrielink-van Ginkel, R.; Verbeek, W.H.J.; Wietsma, W.A.; Kik, C. A genetic map of an interspecific cross in Allium based on amplified fragment length polymorphism (AFLP (TM)) markers. Theor. Appl. Genet. 2000, 100, 118-126. [CrossRef]

16. Jones, N.; Pasakinskiene, I. Genome conflict in the gramineae. New Phytol. 2005, 165, 391-409. [CrossRef]

17. Risso-Pascotto, C.; Pagliarini, M.S.; do Valle, C.B.; Jank, L. Asynchronous meiotic rhythm as the cause of selective chromosome elimination in an interspecific Brachiaria hybrid. Plant Cell Rep. 2004, 22, 945-950. [CrossRef]

18. Kopecky, D.; Simonikova, D.; Ghesquiere, M.; Dolezel, J. Stability of Genome Composition and Recombination between Homoeologous Chromosomes in Festulolium (Festuca x Lolium) Cultivars. Cytogenet. Genome Res. 2017, 151, 106-114. [CrossRef]

19. Kubota, A.; Akiyama, Y.; Fujimori, M.; Kiyoshi, T. No decrease in f ratio (ratio of Festuca-specific genome region to the whole genome) in maternally derived progeny of festulolium (Festuca pratensis $\mathrm{x}$ Lolium species) across generations. Grassl. Sci. 2016, 62, 55-60. [CrossRef]

20. Zwierzykowski, Z.; Zwierzykowska, E.; Taciak, M.; Kosmala, A.; Jones, R.N.; Zwierzykowski, W.; Ksiazczyk, T.; Krajewski, P. Genomic structure and fertility in advanced breeding populations derived from an allotetraploid Festuca pratensis x Lolium perenne cross. Plant Breed. 2011, 130, 476-480. [CrossRef]

21. Kopecky, D.; Havrankova, M.; Loureiro, J.; Castro, S.; Lukaszewski, A.J.; Bartos, J.; Kopecka, J.; Dolezel, J. Physical Distribution of Homoeologous Recombination in Individual Chromosomes of Festuca pratensis in Lolium multiflorum. Cytogenet. Genome Res. 2010, 129, 162-172. [CrossRef]

22. Masoudi-Nejad, A.; Nasuda, S.; McIntosh, R.A.; Endo, T.R. Transfer of rye chromosome segments to wheat by a gametocidal system. Chromosome Res. 2002, 10, 349-357. [CrossRef]

23. Orellana, J.; Cermeno, M.C.; Lacadena, J.R. Meiotic pairingin wheat-rye addition and substitution lines. Can. J. Genet. Cytol. 1984, 26, 25-33. [CrossRef]

24. Naranjo, T. Dynamics of Rye Telomeres in a Wheat Background during Early Meiosis. Cytogenet. Genome Res. 2014, 143, 60-68. [CrossRef] [PubMed]

25. Pernickova, K.; Linc, G.; Gaal, E.; Kopecky, D.; Samajova, O.; Lukaszewski, A.J. Out-of-position telomeres in meiotic leptotene appear responsible for chiasmate pairing in an inversion heterozygote in wheat (Triticum aestivum L.). Chromosoma 2019, 128, 31-39. [CrossRef] [PubMed] 
26. Pickering, R.A.; Timmerman, G.M.; Cromey, M.G.; Melz, G. Characterization of progeny from backcrosses of triploid hybrids between Hordeum vulgare L. (2x) and H. bulbosum L. (4x) to Hordeum vulgare. Theor. Appl. Genet. 1994, 88, 460-464. [CrossRef] [PubMed]

27. Pickering, R. The chromosome stability of Hordeum vulgare L. $x$ H. bulbosum L. chromosome substitution plants grown at 2 temperatures. Hereditas 1994, 121, 39-43. [CrossRef]

28. Lopez-Lavalle, L.A.B.; Brubaker, C.L. Frequency and fidelity of alien chromosome transmission in Gossypium hexaploid bridging populations. Genome 2007, 50, 479-491. [CrossRef]

29. King, J.; Armstead, I.; Harper, J.; King, I. Transmission frequencies of introgressed Festuca pratensis chromosomes and chromosome segments in Lolium perenne. Crop Sci. 2013, 53, 1968-1973. [CrossRef]

(C) 2019 by the authors. Licensee MDPI, Basel, Switzerland. This article is an open access article distributed under the terms and conditions of the Creative Commons Attribution (CC BY) license (http://creativecommons.org/licenses/by/4.0/). 